\title{
A Sequential Analysis on the Online Learning Behaviors of Chinese Adult Learners: Take the KGC Learning Platform as an Example
}

\author{
Junjie Shang ${ }^{(凶)}$, Rui Xiao, and Yuanyuan Zhang \\ Lab of Learning Sciences, Graduate School of Education, Peking University, \\ Beijing 100871, China \\ jjshang@pku.edu.cn
}

\begin{abstract}
The study collected the learning behaviors of 179 adult learners, including video learning, page document learning, assignment submission, and so on. In order to find out the characteristics of online learning behavior of adult learners and provide enlightenment for the improvement of online courses and learning platform design, this paper adopts Lag Sequential Analysis to explore the sequence of learners' behavior transformation. By comparing the behavioral transformation sequence of adult learners with different efficiency, this paper explores the factors influencing learning efficiency. The study found 92 kinds of significant behavioral transformation sequences, reflecting the characteristics of adult learners, such as task-oriented, active exploration and strong self-regulation ability. It is also found that highly efficient learners prefer selective and fast playing pattern, while low efficient learners prefer non-differentiated fast repetition of playing pattern. From this we can get the enlightenment that is helpful to the design of learning platform.
\end{abstract}

Keywords: Learning analysis · Learning behavior sequence $\cdot$ LSA $\cdot$ The learning efficiency $\cdot$ Learning platform

\section{Introduction}

With the continuous development of online education, various Internet enterprises have set up platforms to provide learning opportunities for learners of all ages with various learning needs. At present, most researches on online education, whether on the design of online courses or the learning characteristics of online learners, they all focus on open learning platforms such as MOOC (Chen et al. 2017a), Blackboard (Spivey and Mcmillan 2014), LMS (You 2016) or learning management platforms. The current studies of online education, whether it is about the design of the online course, or online learners' learning characteristics, most of them focused on the open learning platforms MOOC or learning management platforms such as Blackboard and LMS. In the learning platforms like MOOCs, although the number of learners is huge, the drop-out rate is high (Yousef et al. 2015) and effective learners are few.

In China, the development of adult online education is in full swing. According to the data of $2019 \mathrm{H} 1$ iresearch, higher education and vocational training have always 
been the market subject of online education in China, accounting for about $80 \%$ of the total online education market $\left.{ }^{1}\right]$. In China, adult online education, such as vocational training and skill learning, all rely on enterprises' online learning platforms, while the research on online education pays less attention to such learning platforms. Compared with MOOCs and other open learning platforms, there are many unique features of learning in enterprise online learning platforms. For example, due to the profitability of enterprise online learning platforms, there are many unique designs to ensure the learning effect of learners. For example, the KGC learning platform is an enterprise online learning platform, which mainly aims at the skill learning of adults. This platform focuses on the cultivation of practical ability, and does not take test scores as the evaluation standard for learning effect. Instead, it advocates that learners save as much time as possible on the premise of learning skills.

In addition, compared with the main learners of MOOC platform in school, the working adults have strong self-control and clear learning goals. They have a stronger demand for education and training in aspects such as improving their degree, and seeking jobs. These two learning groups have great differences in learning motivation, goal achievement and so on. This study focuses on the online learning platforms in enterprises to explore the different learning characteristics of learners and the characteristics of their behavioral transformation patterns.

\section{Literature Review}

Along with the learning behavior of learners in the learning platform is recorded, the research of learners' behavior, based on objective data, is becoming possible. In the existing studies on learner behavior characteristics, researchers pay more attention to the relationship between learning engagement, learning behavior pattern and learning effect (Zhao et al. 2019; Le et al. 2019). The key point of these studies lies in the representation of learning engagement, learning behavior patterns and learning effects, and the methods used to analyze their relationship.

\subsection{Learning Engagement Behavior}

Limited by the data collected by the learning platform, most researchers use some learning behavior as a characteristic variable to represent learners' learning engagement or explore learning behavior patterns, and most of the characteristic variables used are calculated from the perspectives of time and frequency. For example, Lust et al. (2013) used the time spent by students in LMS on network lectures, network link, tests and other contents as variables representing learning behaviors. Hung and Zhang (2008) used the frequency of accessing course materials and the number of reading messages to indicate the level of learners' efforts. In addition, other studies have used the number of times that learners used the login platform (Le et al. 2019; Healy et al. 2005), the number and time of accessing resources (Morris et al. 2005), the total number of times that learners

${ }^{1}$ I Research page, https://www.iresearch.com.cn/Detail/report?id=3452\&isfree=0, last accessed 2020/2/19. 
visited the course (Asarta and Schmidt 2013) and so on, to reflect learners' learning engagement behaviors. These single behaviors are relatively coarse-grained data, which can hardly reflect learners' cognitive engagement level in detail. These single behaviors reflect learners' learning engagement and learning behavior characteristics rather than learning behavior patterns that should show more about learners' learning behavior path. Previous studies have explored learners' learning path by analyzing learners' behavioral transformation sequence and found learners' backtracking behavior (Hu et al. 2019). In addition, some scholars believe that, compared with the single learning behaviors of learners, the sequence of learning behaviors in the learning process can better reflect the intention and cognitive process of learners' learning behavior trajectory (Yang et al. 2016). Therefore, it can be considered that the behavior transformation sequence can better reflect the learner's learning behavior pattern.

\subsection{Behavior Transformation Sequence and LSA (Lag Sequential Analysis)}

LSA is used in most studies related to sequences of learning behaviors. This method was proposed by Sackett (1978) to test whether the probability of one behavior occurring after another is statistically significant. In the field of education, LSA takes transitional relationships into consideration to identify temporal differences in learning behavior (Chen et al. 2017b). At present, there are mainly the following types of studies related to learning behavior sequence. The first one is the combination of clustering analysis to define learners with different learning patterns and predict their academic performance by clustering the behavior sequence. For example, $\mathrm{Li}$ et al. (2017) explored the online learning behavior sequence and participation pattern of Open University students on Moodle platform through lag sequence analysis. According to the behavior sequence, different online participation patterns of learners are defined, such as low input, shallow level input, performance input, step by step, and random participation. Jiang et al. (2018). used lag sequence analysis to analyze the learning process data on the DEEDS platform, and predicted the learning effect. The second, combined with text analysis, sequence analysis is carried out for the content posted by learners in the forum. For example, Jeong and Allan (2003) conducted sequence analysis of learners' speech content based on text analysis. Similarly, Hou et al. (2009) combined content analysis and sequence analysis to explore learners' learning behavior patterns in the forum. The third is to combine the theoretical framework to explore learners' behavioral transition patterns during knowledge construction (Lan et al. 2012; Lin et al. 2013; Yang et al. 2015). For example, lag sequence analysis is used to analyze the learning patterns of different learners or learners at different stages. Yang et al. (2015) analyzed students' knowledge construction behavior at different activity stages in the collaborative translation process by using lag sequence. Finally, there is a comparative analysis of the differences in learning behavior sequence patterns of learners with high-low achievements (Lai and Hwang 2015). According to the above research, LSA method is an extensive analysis method in the sequence analysis of learning behavior. This study intends to use LSA to explore the learning behavior sequence of Chinese adult learners and analyze the differences of learning behavior sequence of Chinese adult learners with high and low achievement. However, in the above studies, course scores mostly express learners' achievements, which is not suitable for adult learners on the course of KGC learning platform. It is 
necessary to combine the characteristics of learners, curriculum and learning platform to determine the form of learning effect.

\subsection{The Learning Effect of Adult Learners in KGC Learning Platform}

Most studies have used test scores (Lin et al. 2013), or self-report through questionnaires (Yang 2016) to reflect learning effect. The score can only reflect the learning effect from the learning result dimension, and the learning efficiency in the learning process is difficult to reflect. In adult learning scenarios such as vocational training, learners not only pay attention to their performance and knowledge, but also pay attention to learning efficiency and time cost. This is the biggest difference between the adult vocational training learning scene and the general online learning scene in the aspect of learning effect. For example, in the KGC learning platform, the design of it is guided by "mastering learning theory", believing that all learners can learn and master relevant knowledge. It's just that the amount of time each person spends is different, and learners should move forward in small steps and strictly monitor the outcome of each step. Only by mastering the current knowledge and skills can learners continue to learn. Under this learning platform, the learning effect is not reflected by test scores, but by the time it takes the learner to reach a certain stage. The shorter the time, the stronger the learner's learning ability, and the higher the learning efficiency. Compared with grades, it is more effective to reflect learning effect from time dimension for vocational skill training. Vocational training courses emphasize a results-oriented approach, unlike many courses in MOOCs. For example, in the MOOC platform of Chinese universities, the scores of most courses are the comprehensive weight of test scores and homework scores, which also contains the input of learning behaviors and other processes at ordinary times. In addition, exams have certain uncertainties, which cannot fully reflect the learning effect of learners. In vocational skills training, the purpose of learners is to master relevant knowledge and skills as soon as possible, so in such learning scenarios, it is more effective to use the time spent in mastering relevant knowledge and skills to reflect the learning effect.

To sum up, we can find that LSA for behavior sequence exploration is a relatively mature analysis technology. Though the behavior sequential analysis, different learning behavior participation patterns can be found. However, most of the above studies were conducted on the courses on open learning platforms, such as MOOCs, and most of them used test scores as learning effects to explore the differences in learning effects of learners with different behavior sequences. For vocational skills training courses in enterprises, learners are mostly adults with clear goals and strong self-control, and the focus of learning effect is not only the mastery of knowledge and skills, but also the cost of time. In such a learning scene, what kind of learning behavior sequence will exist in learners and what kind of learning characteristics will be represented. In addition, studies have also shown that different types of online learning resources can affect learners' learning time and frequency (Yousef et al. 2015). Therefore, it can be seen that different types of learning content may also have a certain impact on learners' learning behavior. Therefore, the purpose of this study is to explore the learning behavior characteristics of adult learners in the context of vocational skills learning, and whether the differences in curriculum content have an impact on them. Further, explore what kind of learning behavior sequence do learners with different learning efficiency have, In order to find 
ways to improve the learning effectiveness and learning efficiency of learners, and to provide Suggestions and guidance for the design of learning platforms and the learning of online learners.

\section{Methodology}

\subsection{Research Questions}

The research collected the data generated by 179 learners in two courses in the KGC learning platform: elementary artificial intelligence: basics of Python introduction(Python introduction) and introduction to data analysis(data analysis). This study explores the behavior sequence of online learners based on this learning platform by using LSA. The questions to be answered in this study are as follows:

1) What are the characteristics of learner's behavior sequence under this learning platform? What learning state can it reflect?

2) In different courses, what are the differences between learners' learning behavior sequences?

3) What are the differences between learners with different efficiency in learning behavior sequence?

\subsection{Learning Process of Learners on the KGC Learning Platform}

In this case, the learning platform provides online learners with video, documents and other learning resources, as well as calendar module, question and answer module, learning dashboard and so on to assist learners in learning. The main interface of the learning platform is shown in the Fig. 1. This learning platform is characterized by its design of learning baffle based on the mastery learning theory. Learners must master the contents of the previous unit before they can move on to the next unit. In this way, learners can learn the content of each section steadily, so as to achieve a better learning effect. Only by successfully completing the assignments in the previous unit can learners begin to learn the next unit. (Figure 2) In each unit, learners learn mainly by viewing documents, videos and other materials. Besides, the platform also provides learners with several simple test questions to recall the key contents. In addition, learners can also arrange and understand their learning process by adding learning calendar, viewing learning progress, learning duration and other information displayed in the learning dashboard.

\subsection{Data Cleaning and Analysis}

The learner's learning process is independent, and the learning starts and ends at different times. The study collected 1278,145 log data from 179 learners who successfully completed the two courses from October 2018 to October 2019. After deduplication and cleaning up the invalid data, there are 914938 log data left. According to the learning content types and functions, the study classifies learners' learning behaviors into 7 categories and 26 behaviors in total. The classification and coding are shown in Table 1 


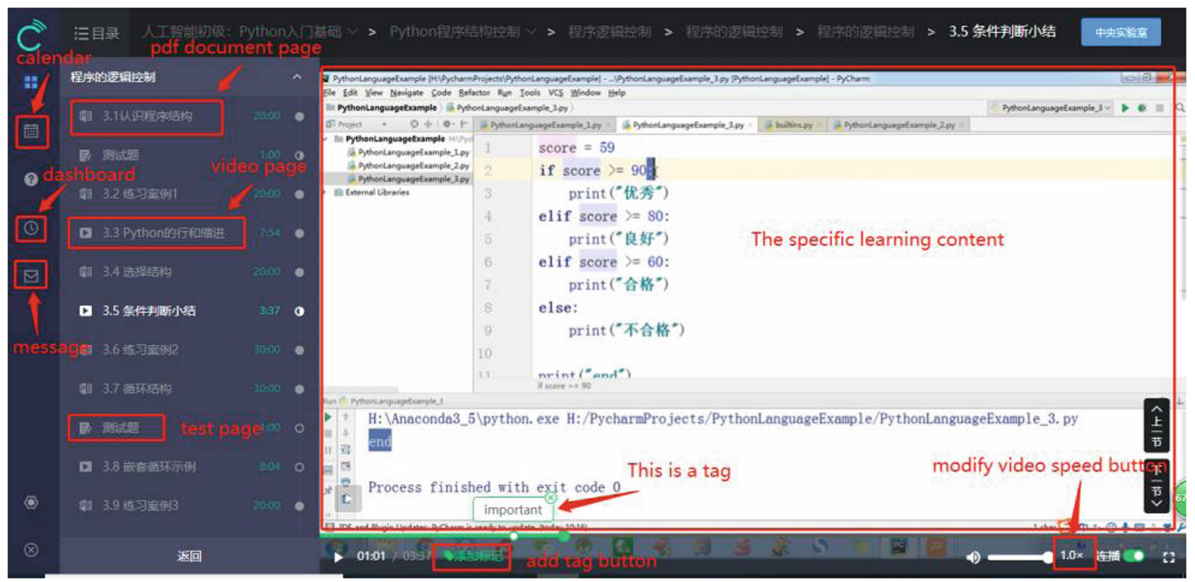

Fig. 1. The main interface of the learning platform

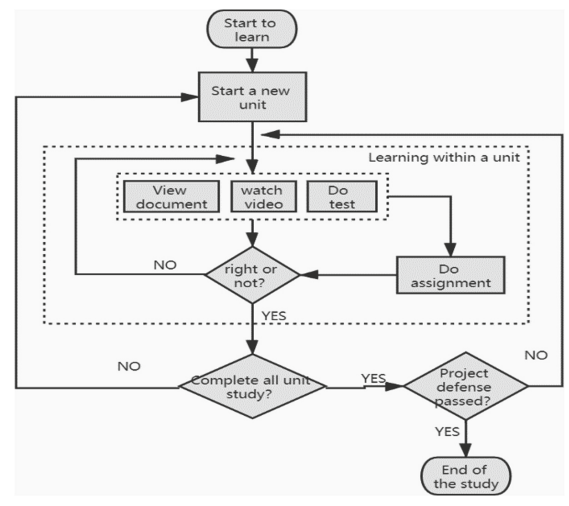

Fig. 2. The course learning process on the KGC learning platform

below. Video is the main learning content of learners. At the same time, according to some summary document pages and test questions provided by the course, learners can conduct a summary review of the content of the video. In each unit, the assignments of the work page are required to be completed by the learner, so that the learner can also know how well he/she has achieved in the unit.

According to the principle of sequence analysis, the transformation from one behavior to another is defined as a sequence of behaviors. The code combination of the two behaviors is used to represent the sequence, and the order of behavior coding in a combination represents the direction of behavior transformation in that sequence. For example, learners enter the document page (ES) first, and then exit the document page (OS), then the behavior sequence is ES $\rightarrow$ OS. According to the above 26 kinds of behaviors, there are 676 behavioral sequences in theory, but only 443 behavioral sequences are actually produced. 
Table 1. Code for 26 learning behaviors

\begin{tabular}{|c|c|c|c|}
\hline Category & Content type & Learned behavior & Coding \\
\hline \multirow{7}{*}{$\begin{array}{l}\text { Content } \\
\text { learning }\end{array}$} & \multirow[t]{7}{*}{ Video } & Add a tag to the video & AT \\
\hline & & Enter the video learning & EV \\
\hline & & Exit video learning & $\mathrm{OV}$ \\
\hline & & Pause video learning & PV \\
\hline & & Continue video learning & $\mathrm{CV}$ \\
\hline & & Modify the speed of the video & MS \\
\hline & & $\begin{array}{l}\text { Modify the video progress bar to selectively } \\
\text { play the content at a certain time }\end{array}$ & MVP \\
\hline \multirow{6}{*}{$\begin{array}{l}\text { Summary of } \\
\text { learning }\end{array}$} & \multirow{3}{*}{$\begin{array}{l}\text { Summary document } \\
\text { page }\end{array}$} & Enter the summary document page & ES \\
\hline & & Exit the summary document page & OS \\
\hline & & Download code resource & DR \\
\hline & \multirow[t]{3}{*}{ Test } & Enter the test & ET \\
\hline & & Exit the test & OT \\
\hline & & Submit the test & ST \\
\hline \multirow{7}{*}{$\begin{array}{l}\text { Effect of } \\
\text { learning }\end{array}$} & \multirow{7}{*}{$\begin{array}{l}\text { The assignments of } \\
\text { the work page }\end{array}$} & Enter the work page & EW \\
\hline & & Do the assignments of the work page & DW \\
\hline & & Submit the work & SW \\
\hline & & Exit the work page & OW \\
\hline & & Apply for reply of the whole course work & AR \\
\hline & & $\begin{array}{l}\text { Quit application for reply of the whole } \\
\text { course work }\end{array}$ & QR \\
\hline & & $\begin{array}{l}\text { Submit application for reply of the whole } \\
\text { course work }\end{array}$ & SR \\
\hline \multirow[t]{6}{*}{$\begin{array}{l}\text { Assisted } \\
\text { learning }\end{array}$} & \multirow[t]{2}{*}{ Learning dashboard } & $\begin{array}{l}\text { View learning progress in the learning } \\
\text { dashboard }\end{array}$ & VP \\
\hline & & $\begin{array}{l}\text { View learning duration in the learning } \\
\text { dashboard }\end{array}$ & VT \\
\hline & \multirow[t]{2}{*}{ Learning calendar } & View learning calendar & $\mathrm{VC}$ \\
\hline & & Add learning calendar & AC \\
\hline & \multirow[t]{2}{*}{ Message } & View message & VM \\
\hline & & View question and answer module & VQ \\
\hline
\end{tabular}




\section{Result}

\subsection{Learner Behavioral Sequence Characteristics}

According to the LSA method, the GSEQ5.1 software was used to make a frequency table of behavior transformation according 26 learning behaviors, and the standard score conversion was performed to obtain the adjusted residual table (Table 2). When the adjusted residuals value of the behavioral transformation sequence is higher than 1.96, then it was significant at the level of 0.05 . It indicates that the occurrence of the behavioral transformation sequence is significant (Bakeman and Quera 1995). The combination of frequency $n>30$ was used to screen out the behavioral transformation sequences that reached the significance, and the results showed that only 24 of the 26 behaviors had achieved the significance, and a total of 95 behavioral transformation sequences had achieved the significance. Gephi0.9.2 visualizes these significant behavioral transformation sequences through the Fruchterman Reingold layout, resulting in Fig. 3.

Table 2. The adjusted residual table (Part of the whole table)

\begin{tabular}{l|r|r|l|l}
\hline & PV & CV & MS & MVP \\
\hline PV & -151.09 & $465.1^{*}$ & -11.03 & $16.66^{*}$ \\
\hline CV & $302.95^{*}$ & -189.35 & $29.99^{*}$ & $202.8^{*}$ \\
\hline MS & $47.05^{*}$ & -14.02 & -3.32 & $33.81^{*}$ \\
\hline MVP & $180.44^{*}$ & -16.02 & $29.33^{*}$ & -56.63 \\
\hline *P $<0.05$
\end{tabular}

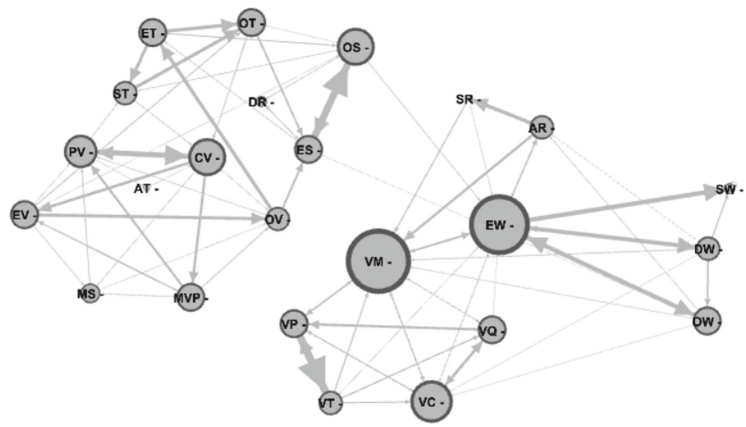

Fig. 3. The sequence diagram of students' overall learning behavior transformation

In Fig. 3, there are 24 nodes, representing 24 learning behaviors, and 95 edges, representing 92 behavioral transformation sequences. The direction of the arrow represents the direction of the behavior transformation, and the thickness of the line represents the probability of the behavior transformation. The size of the node shows the number of 
degrees of that node. Through the overall sequence diagram of learning behavior transformation of all learners, we can see that viewing message (VM) and entering the work page $(\mathrm{EW})$ are the two largest nodes. It indicates that these two behaviors are the most central behaviors of behavior transformation, and in this platform, learners are driven by homework and good at paying attention to information. According to Fig. 4, it can be seen that there are more wires between the behavior nodes related to Content learning. The behavior nodes related to Summary of learning, Effect of learning and Assisted learning also show similar characteristics, which reflects that learners have more behavioral transformation when learning the same type of content. It may be caused by the setting of the order of learning content on the platform itself. In addition, there are many transformations between Effect of learning and Assisted learning. Moreover, according to Fig. 5, the highlighted nodes connected to the EW or VM nodes are almost "effect of learning" and "assisted learning". it can be found that the transformation between the assisted learning behavior and the work-related behavior is relatively frequent. This indicates that learners' assisted learning behavior is mainly for completing the assignments of the work page, which reflects learners' strong task-oriented learning characteristics under the platform.

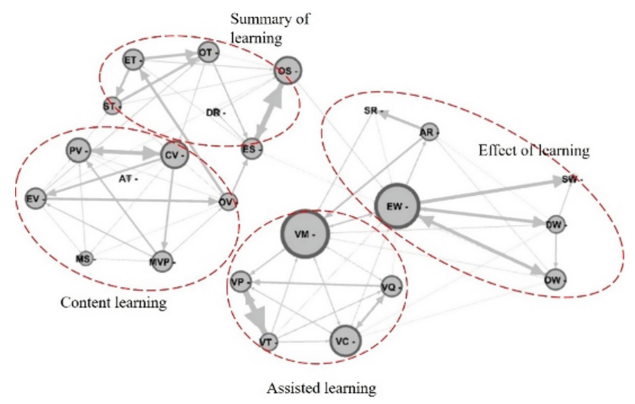

Fig. 4. Sequence diagram of students' behavior transformation to different types of learning content

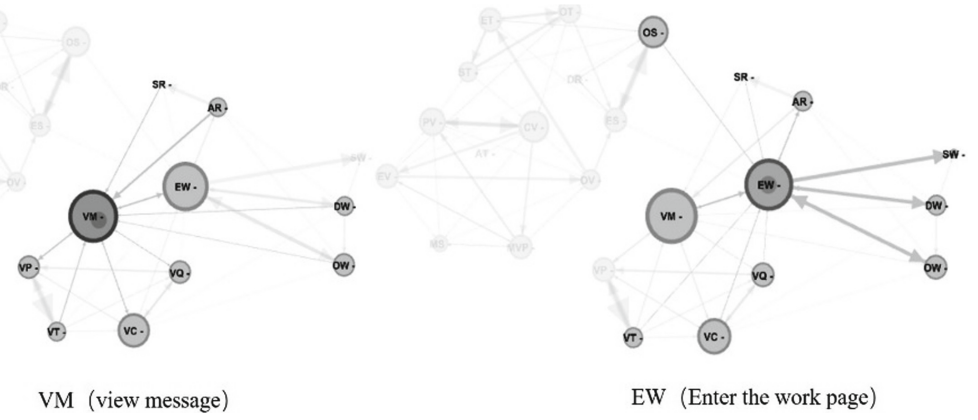

Fig. 5. Behavioral transformation network centered VM and EW respectively 


\subsection{In Different Courses, the Difference of Learners' Learning Behavior Sequence}

The content and instructional goal of the course may influence the sequence of the learner's behavior transition. According to the content and instructional goal of the two courses, it is found that the instructional goal of Python introduction is to let learners learn to write Python code. it requires learners to write more actual code for practice. However, the instructional goal of data analysis is to enable learners to learn the thinking and methods of data analysis. Although the assignments of work page also requires the actual writing of Python code, this course is more inclined to method learning than the course of Python introduction. Therefore, the two courses Python introduction and data analysis are defined as code-drill courses and method learning courses. In order to know the differences of learners' learning behavior sequence in different courses, the study further explored what kind of behavioral transformation sequences these 179 learners had in the two courses.

The same method is used to analyze the behavioral data of learners in these two courses, and Fig. 6 and Fig. 7 are obtained. Through the comparison of the two graphs, it can be found that the behavioral transformation patterns of learners in the two courses are similar in the whole. And the difference is mainly reflected in the transformation between the behaviors related to video learning and assignment completion. Compared with method learning courses, there are more connections between behaviors related to video learning and completing assignment, assisted learning in code-drill course. In combination with the above findings, learners' assisted learning behaviors are mainly for completing assignment, indicating that in code-drill courses, learners frequently switch between assignment completion and video learning, and learners often backtrack the learning video when completing assignment. It reflects that learners in the code-drill course have the characteristics of strong task-oriented and backtrack learning, while in the method learning course, such backtrack learning behavior is less.

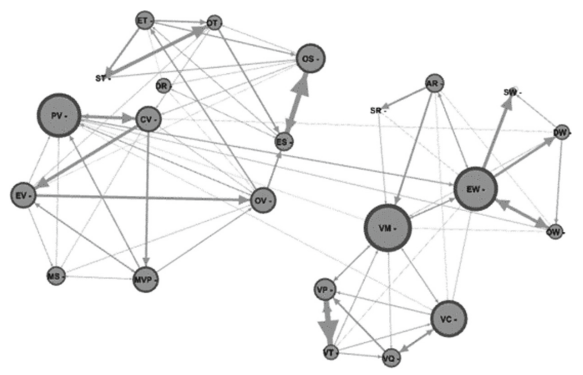

Fig. 6. Sequence diagram of learner behavior transformation in code-drill course

\subsection{Differences in Learning Behavior Sequences of Learners with Different Efficiency}

In addition to being influenced by the course itself, learners themselves are the most important influencing factor of the behavior sequence. Learners with different efficiency 


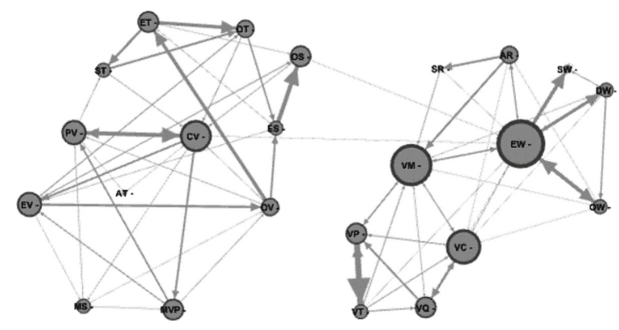

Fig. 7. Sequence diagram of learner behavior transformation in method learning course

may have different learning styles. The study aims to find out the differences in learning styles of learners with different efficiency by exploring the differences in learning behavior sequences of learners with different efficiency, so as to put forward Suggestions conducive to improving learning efficiency.

Distinguish Between Highly and Low Efficient Groups. In order to avoid the influence of different course on learning behavior sequence, this part of the study adopts the learning behavior data of learners in the code-drill course Python introduction. The study differentiates the efficiency of learners according to the time it takes them to complete the course. The average length of time for learners to complete the course is $\mathrm{M}$ $=69.15 \mathrm{~h}$, and the standard deviation is 43.49 . Learners who completed the course in less than $25.66 \mathrm{~h}$ (M-SD) were classified as highly efficient learners, while learners who completed the course in more than $112.64 \mathrm{~h}(\mathrm{M}+\mathrm{SD})$ were classified as low efficient learners. Finally, there were 30 learners in the highly efficient group and 25 learners in the low efficient group.

\section{Commonality of Behavior Transformation Sequence in Highly and Low Efficient}

Group. According to the above research results, it can be found that the main learning behaviors of learners are related to document pages, videos and assignments. To further explore the differences of learning behavior transformation between the two groups in the three aspects, a total of 11 behaviors were selected. The result is shown in Fig. 8. As can be seen from the Fig. 8, there was no significant difference in the behavioral transformation patterns of the highly and low efficient groups as a whole. The commonality of these two groups is that in video learning, they not just passively accept knowledge, but also have some behaviors such as pause video learning (PV), modify the video progress bar to selectively play the content at a certain time (MVP). This can reflect that learners have the characteristics of active learning no matter their efficiency is high or low.

In addition, $\mathrm{PV} \rightarrow \mathrm{EW}$ and $\mathrm{OS} \rightarrow \mathrm{EW}$, this two significant behavioral transformations, can reflect learners' backtracking behavior towards the previous learning content when doing assignments. The significant behavioral transformation of OS $\rightarrow \mathrm{CV}$ indicates that learners have gone through a series of behaviors including $\mathrm{PV} \rightarrow \mathrm{ES} \rightarrow \mathrm{OS} \rightarrow$ $\mathrm{CV}$, which reflects learners' learning transformation between documents and videos. In this platform, the learning document is the summary of the key content in the video. For this course, the video can explain the operation process more clearly, but it takes time. And the documentation refines the operation code so that learners can quickly access 



Fig. 8. Learning behavior transformation patterns in different efficiency groups

the method, but there are no detailed steps. Learners switch back and forth between the two types of learning materials, showing learners' active thinking and exploration in the learning process.

\section{Differences of Behavior Transformation Sequence in Highly and Low Efficient}

Group. Although the highly and low efficient groups are similar in the whole of learning behavior transformation, there are still some differences, mainly reflected in the part shown in circle in Fig. 8. It's about modify the speed of the video (MS) and modify the video progress bar to selectively play the content at a certain time (MVP). The transitions between this two behaviors and the behaviors of pause video learning (PV) and continue video learning $(\mathrm{CV})$ is much more in the highly efficient group. Compared with the low efficient group, the highly efficient group showed the following significant behavioral transformations: CV (Continue video learning) $\rightarrow$ MS (Modify the speed of the video), MS $\rightarrow$ PV (Pause video learning), MS $\rightarrow$ MVP (Modify the video progress bar to selectively play the content at a certain time), MVP $\rightarrow$ MS. This indicates that during the process of watching the video, there is an intersecting behavior transformation between the four behaviors of pause, continue, modify the video progress bar and modify speed, which reflects that the highly efficient group adopts different learning speeds for different parts of the same video. The significant behavioral transitions associated with the low efficient group were EV (Enter video learning) $\rightarrow$ MS, MS $\rightarrow$ OV (Exit video learning). This indicates that in the video learning process, after modifying the playing speed, the low efficient group kept learning at the same speed until the end of the video.

Combined with the investigation on all learners modifying the video playing speed, $83.76 \%$ of the video playing speed adjustment is to adjust the speed to higher than the normal playing speed. Among them, the frequency of adjusting the playing speed of the low efficient group was nearly three times that of the highly efficient group, and the average playback frequency of the same video was 2.7 times that of the highly efficient group. Furthermore, according to the accuracy of answering the test for the first time in the highly and low efficient group (see Table 3). It can be concluded that the highly and low efficient group preferred to play the video at a faster speed in video learning. But the highly efficient group played the video quickly and purposefully for some part of the content, and had a higher learning effect. The low efficient group adopted the fast speed without distinction, and returned to repeat learning when the learning effect was low. Therefore, the difference between highly and low efficient groups is mainly reflected in the learning efficiency of videos. The highly efficient group adopted 
a selective and fast learning method, choosing the main learning content and learning speed more purposefully. The low efficient group adopted the non-differentiated fast repetition learning method, while the content learning method was fast but repeated more times.

Table 3. Highly efficient group versus low efficient group

\begin{tabular}{l|l|l}
\hline & Highly efficient group & Low efficient group \\
\hline $\begin{array}{l}\text { The average number of times that a video is } \\
\text { played at a speed faster than normal }\end{array}$ & 1.37 & 3.8 \\
$\begin{array}{l}\text { The average number of times a video is } \\
\text { played }\end{array}$ & 2.39 & 6.51 \\
\hline \begin{tabular}{l} 
The first correct rate of test \\
\hline
\end{tabular} & $76.45 \%$ & $61.32 \%$ \\
\hline
\end{tabular}

\section{Discussion}

Through the study of 179 adult learners, we found that there are many significant learning behavior sequences in the learning process of adult learners in this learning platform. These behavior sequences can significantly reflect that adult learners are driven by task and have strong initiative and self-regulation ability, which is one of the characteristics of excellent learners. Thus, one of the characteristics of online learners is that they are driven by assignments/tasks and have strong goal orientation.

There are differences in the sequence of learners' behaviors in different types of courses. Learners in code-drill courses have strong task-oriented and retrospective learning characteristics, while in method learning courses, such retrospective learning behaviors are rare. This difference may be due to the fact that there are more operational details involved in the code-drill courses, and learners need to constantly recall the relevant details when using what they have learned, while in the method learning courses, after they understand the methods and ideas, they can directly use what they have learned without too much retrospection. According to this difference, in the course design and platform design, learning resources can be arranged in combination with the nature of the course. So as to facilitate learners' learning backtracking behavior, such as providing learners with appropriate summary materials and improving learners' backtracking efficiency.

The study found that there was little difference in the overall behavior transformation pattern of the highly and low efficient group. This indicates that the behavior patterns of learners in this learning platform are similar, but there are some differences in efficiency, and there is no marginal group in learning. This result is different from the disengaged learners (Rodrigues et al. 2016) that appears in MOOC studies. On the one hand, this is because the learner groups are different, and their learning motivation is different. On the other hand, the main reason is the baffle design of the learning platform in this case study, which avoids the "wandering" and "jumping learning" of learners. 
In addition, some studies have pointed out that learners in online learning have poor self-monitoring ability and procrastination habit (Hu et al. 2019). In view of this phenomenon, on the one hand, the reward and punishment mechanism should be added in the course design to promote learners' enthusiasm in learning. On the other hand, from the platform design, baffle control can be adopted, which can more mobilize the initiative of learners and reduce their ineffective browsing behavior. In addition, the overall behavior patterns of the highly and low efficient groups were not significantly different, indicating that the most frequent and common behavior transformation patterns were not the main factors affecting the learning effect. As Kinnebrew and Loretz (2013), found, almost all of the most frequent activity patterns in the high and low achievement group were the same or similar. This indicates that the factors influencing learners' learning effect may not be the overall behavioral pattern or the most frequent behavioral transformation pattern, but some key behavioral sequence pattern, such as the video playing behavior patterns found in this study. The highly efficient group prefer to the selective and fast playing pattern, which not only saves time and improves efficiency, but also selectively adjusts itself. And they adopts different learning speeds for different contents to reduce its cognitive load. However, in the low efficient group, non-differentiated fast repetition of playing increased the cognitive load of their learning, resulting in inefficient learning. According to the results, online adult learners can be provided with appropriate learning guidance, so as to prevent them from using indiscriminate and fast playback to save time and learning inefficiency. At the same time, the results provide some inspiration for the developers of video learning materials. In video production, different playing speeds can be presented for different difficult parts of the same video, so that learners can learn video efficiently. At the same time, it also provides inspiration for the feedback design of learning platform. The learning platform can provide feedback to learners about the video learning situation, such as the visual statistical graph of learning times, learning speed, learning time, and learning level in class or group. These can guide students to pay attention to the video learning method, timely find their own learning style problems, and timely adjustment.

\section{Conclusion}

This study explores the online behavior transformation patterns of adult learners and finds the characteristics of strong task orientation of adult learners. Moreover, this paper explores the differences in learners' behavior sequences from the dimension of course type and learning efficiency, and finds that there are some differences in learners' backtracking behaviors in the code-drill courses and method learning courses. Learners in code-drill courses have the characteristics of strong task-oriented and retrospective learning, while in method learning courses, such retrospective learning behaviors are rare. Additionally, there are some differences in the video playing patterns among learners in the highly and low efficient group, which may be the main factor affecting the learning efficiency.

Since the conclusion is made by comparing the behavior sequence transformation diagram of the highly and low efficient group, further verification is needed. Besides, there were other limitations, such as the classification of course types. The classification 
adopted in this study is defined from the perspective of the instructional goals of the course. Later studies can further refine the course types from the knowledge types, so as to further explore which behavioral patterns learners should adopt or which behavioral sequences can have better learning effects for different types of learning contents.

Acknowledgements. This study is funded by Peking University 2020 Novel Coronavirusinfected Pneumonia Prevention and Control (Special) Project "Research on Learning Mechanisms and Key Technologies to Improve the Quality of Online Education (No. 35)".

\section{References}

Asarta, C.J., Schmidt, J.R.: Access patterns of online materials in a blended course. Decis. Sci. J. Innovative Educ. 11(1), 107-123 (2013)

Bakeman, R., Quera, V.: Analyzing Interaction: Sequential Analysis with SDIS and GSEQ. Cambridge University Press, Cambridge (1995)

Chen, B., Fan, Y., Zhang, G., Wang, Q.: Examining motivations and self-regulated learning strategies of returning MOOCs learners. In: International Learning Analytics \& Knowledge Conference, pp. 542-543. ACM (2017a)

Chen, B., Resendes, M., Chai, C.S., Hong, H.Y.: Two tales of time: uncovering the significance of sequential patterns among contribution types in knowledge-building discourse. Interactive Learn. Environ. 25(2), 162-175 (2017b)

Healy, D., et al.: Electronic learning can facilitate student performance in undergraduate surgical education: a prospective observational study. BMC Med. Educ. 5(23), 1-8 (2005)

Hung, J.L., Zhang, K.: Revealing online learning behaviors and activity patterns and making predictions with data mining techniques in online teaching. MERLOT J. Online Learn. Teach. 4(4), 426-437 (2008)

Hou, H.T., Sung, Y.T., Chang, K.E.: Exploring the behavioral patterns of an online knowledgesharing discussion activity among teachers with problem-solving strategy. Teach. Teach. Educ. 25(1), 108 (2009)

Hu, D., Zhang, M., Zheng, Q.: Visualized analysis of online learners' activity path through lag sequence analysis. e-Educ. Res. 40(05), 57-65 (2019)

Jeong, Allan, C.: The sequential analysis of group interaction and critical thinking in online. Am. J. Distance Educ. 17(1), 25-43 (2003)

Kinnebrew, J.S., Loretz, K.M., Biswas, G.: A contextualized, differential sequence mining method to derive students' learning behavior patterns (2013). https://www.researchgate.net/publication/ 268437308

Jiang, B., Gao, M., Chen, Z., Wang, X.: Learning process analysis and learning achievement prediction with behavioral sequences. Mod. Distance Educ. 31(02), 103-112 (2018)

Lan, Y.F., Tsai, P.W., Yang, S.H., Hung, C.L.: Comparing the social knowledge construction behavioral patterns of problem-based online asynchronous discussion in e/m-learning environments. Comput. Educ. 59(4), 1122-1135 (2012)

Lin, T.J., Duh, H.B.L., Li, N., Wang, H.Y., Tsai, C.C.: An investigation of learners' collaborative knowledge construction performances and behavior patterns in an augmented reality simulation system. Comput. Educ. 68, 314-321 (2013)

Lust, G., Elen, J., Clarebout, G.: Regulation of tool-use within a blended course: student differences and performance effects. Comput. Educ. 60(1), 385-395 (2013)

Lai, C.L., Hwang, G.J.: A spreadsheet-based visualized Mind tool for improving students' learning performance in identifying relationships between numerical variables. Interactive Learn. Environ. 23(2), 230-249 (2015) 
Li, S., Zhong, Y., Yu, C., Cheng Gang, G., Wei, S.: Exploring the online learning participation behavior pattern based on behavioral sequence analysis. China Educ. Technol. 03, 88-95 (2017)

Le, H., Fan, Y., Jia, J., Wang, Q.: How do excellent MOOC learners learn_—mining learning behavior patterns in MOOC. China Educ. Technol. 385(02), 77-84 (2019)

Morris, L.V., Finnegan, C.L., Wu, S.: Tracking student behavior, persistence, and achievement in online courses. Internet High. Educ. 8, 221-231 (2005)

Rodrigues, R.L., et al.: Discovering level of participation in MOOCs through clusters analysis. In: IEEE International Conference on Advanced Learning Technologies. IEEE (2016)

Sackett, G.P.: Observing Behavior: Theory and applications in mental retardation. University Park Press, Baltimore (1978)

Spivey, M.F., Mcmillan, J.J.: Using the blackboard course management system to analyze student effort and performance. J. Financial Educ. 04, 21-28 (2014)

Yang, X., Li, J., Guo, X., Li, X.: Group interactive network and behavioral patterns in online English-to-Chinese cooperative translation activity. Internet High. Educ. 25, 28-36 (2015)

Yousef, A.M.F., Chatti, M.A., Wosnitza, M., Schroeder, U.: A cluster analysis of MOOC stakeholder perspectives. Int. J. Educ. Technol. High. Educ. 12(1), 74-90 (2015)

Yang, X., Guo, X., Yu, S.: Student-generated content in college teaching: content quality, behavioural pattern and learning performance. J. Comput. Assist. Learn. 32(1), 1-15 (2016)

Yang, X.M., Wang, H., Li, J.: The application of lag sequential analysis method in analyzing learning behavior. China Educ. Technol. 37(2), 17-23 (2016)

You, J.W.: Identifying significant indicators using LMS data to predict course achievement in online learning. Internet High. Educ. 29, 23-30 (2016)

Zhao, C., Li, M., Shu, F., Huang, Y.: Research on models of participation in online learning resources and learning effectiveness. Mod. Distance Educ. 41(4), 20-27 (2019) 